\title{
Diffuse alveolar hemorrhage secondary to plastic fume exposure: A case report
}

\author{
Omkar K. Choudhari ${ }^{1}$, Umesh Chandra Ojha ${ }^{2,3}$, Dipti Gothi ${ }^{3}$, Sonam Spalgais ${ }^{4}$, Devesh Pratap Singh ${ }^{5}$, \\ Anita Rani ${ }^{1}$ \\ ${ }^{1}$ Department of Clinical Biochemistry, Vardhman Mahavir Medical College and Safdarjung Hospital, New Delhi; \\ ${ }^{2}$ Institute of Occupational Health and Environmental Research, Basaidarapur, New Delhi; ${ }^{3}$ Department of Respiratory \\ Medicine, ESIC Post Graduate Institute Medical Science and Research, New Delhi; ${ }^{4}$ Department of Pulmonary \\ Medicine, Vallabhbhai Patel Chest Institute, University of Delhi, New Delhi; ${ }^{5}$ Department of Respiratory Medicine, \\ Mayo Institute of Medical Sciences, Barabanki, India
}

\begin{abstract}
A 31-year non-smoker man, working in plastic making industry for 12 years presented with cough and streaking hemoptysis for 2 days. Computed tomography (CT) of chest showed patchy ground glass opacities with interlobular septal thickening in bilateral lung parenchyma. Fiber optic bronchoscopy (FOB) was done. Sequential lavage was taken which showed progressively increas-
\end{abstract}

Correspondence: Omkar Kalidasrao Choudhari, Department of Clinical Biochemistry, Vardhman Mahavir Medical College and Safdarjung Hospital, New Delhi, India.

Tel. +91.9958166730 .

E-mail: omkarchoudhari@yahoo.com

Key words: Alveolar hemorrhage; plastic; diffusion capacity for carbon monoxide (DLCO).

Contributions: OC, data collecting, analysis of data, interpretation of data, manuscript drafting and writing; UCO, data collecting, analysis of data, interpretation of data, manuscript writing, final proof reading; DG, interpretation of data, manuscript writing, critically revising data and final proof reading; SS, interpretation of data, manuscript writing, final proof reading; DPS, data collecting, analysis of data, interpretation of data, manuscript drafting; AR, critically revising data and final proof reading.

Conflict of interest: The authors declare no conflict of interest.

Informed consent: Patients consent obtained.

Conference presentation: presented in a conference OCCUCON 2017, New Delhi.

Received for publication: 12 April 2020.

Accepted for publication: 22 May 2020.

${ }^{\circ}$ Copyright: the Author(s), 2020

Licensee PAGEPress, Italy

Monaldi Archives for Chest Disease 2020; 90:1304

doi: 10.4081/monaldi.2020.1304

This article is distributed under the terms of the Creative Commons Attribution Noncommercial License (by-nc 4.0) which permits any noncommercial use, distribution, and reproduction in any medium, provided the original author(s) and source are credited. ing hemorrhagic fluid. His diffusion capacity for carbon monoxide (DLCO) was $38.08 \mathrm{~mL} / \mathrm{mmHg} / \mathrm{Mi}(126 \%)$ predicted on day 2 of admission, $32.36 \mathrm{ml} / \mathrm{mmHg} / \mathrm{Mi}(106 \%)$ predicted on discharge and $39.63 \mathrm{~mL} / \mathrm{mmHg} / \mathrm{Mi}(130 \%)$ predicted on going back to work. He was diagnosed with plastic fume exposure related pulmonary alveolar hemorrhage.

\section{Introduction}

In the era of industrialization, plastic industries have flourished. Being one of the relatively inexpensive polymers, plastic has taken over a significant place in our daily routine as it can be molded to any desired shape. Most of the cases of plastic fumes exposure are undiagnosed. The presentation is initially mild and non- specific. Persistent exposure can lead to devastating manifestations leading to significant respiratory impairment. Plastic fumes have been culprit since long in the etiopathogenesis of various diseases ranging from occupational asthma to diffuse alveolar hemorrhage secondary to capillaritis [1-4]. The poly vinyl chloride (PVC) is toxic and carcinogenic polymer of plastic [5]. Trimellitic anhydride (TMA) is low molecular weight chemical involved in the manufacturing of plasticizers for PVC resins [6]. Workers not using industrial respirators or personal protective equipment (PPE) typically get exposed to these toxic fumes causing diffuse alveolar hemorrhage (DAH) like in our case.

\section{Case Report}

A 31-year-old non-addict man, presented with hemoptysis for 2 days. There was no history of fever, atopy, childhood pneumonia or anti tubercular treatment (ATT) in past. There was no history of any medication or drug abuse. He did not give any history of trauma or surgical intervention. There was no significant family history of any disease. On examination his oxygen saturation was $94 \%$ at room air, blood pressure was $110 / 80 \mathrm{mmHg}$, respiratory rate was $20 / \mathrm{min}$ and pulse rate $102 / \mathrm{min}$. His respiratory system examination showed bilateral infra-scapular rhonchi. His general examination was normal. Chest radiograph was normal (Figure 1). Complete blood count and routine biochemical investigations were normal. Computed Tomography (CT) thorax showed bilateral ground glass opacities with interlobular septal thickening 
(Figure 2). Fiber optic bronchoscopy (FOB) was done. No intraluminal growth seen on bronchoscopy. Sequential lavage was taken which showed progressively hemorrhagic fluid characteristic of alveolar hemorrhage (Figure 3) [7,8]. Bronchial aspirate showed alveolar macrophages positive for hemosiderin. The spirometry on day 2 of presentation showed forced expiratory volume in 1 second (FEV1) - $3.00 \mathrm{~L}$ (83\%), forced vital capacity (FVC) - 4.67L $(109 \%)$ and FEV1/FVC ratio of $64.40(79 \%)$. The diffusion capacity of carbon monoxide (DLCO) was 38.08(126\%).

Antinuclear antibody (ANA) and double standard deoxyribose nucleic acid (Ds DNA) antibody were negative. Cytoplasmic-anti nuclear cytoplasmic antibody (C-ANCA) and perinuclear antinuclear cytoplasmic antibody (P-ANCA) was $3.88(\mathrm{~N}<7)$ and 4.32 $(\mathrm{N}<7)$ respectively. Anti-glomerular basement membrane (GBM) antibody $5.90 \mathrm{U} / \mathrm{mL}$ was negative $(\mathrm{N}=0-20 \mathrm{U} / \mathrm{mL})$. His Non Structural protein $1(\mathrm{NS} 1)$ antigen and Dengue $\operatorname{IgM}$ and $\mathrm{IgG}$ were negative. Enzyme linked immune-sorbent assay for human immunodeficiency virus was also negative. Urine routine microscopy was normal. The two-dimensional echocardiography (2D ECHO) showed normal ejection fraction with no valvular abnormality. No significant abnormality was observed by otorhinolaryngologist, ophthalmologist and dermatologist on their respective consultation.

He was advised to refrain from work, which improved patient's condition: DLCO decreased to $32.36 \mathrm{~mL} / \mathrm{mmHg} / \mathrm{Mi}$ $(106 \%)$. However the patient went back to work and developed hemoptysis again. Patient was readmitted, after stabilization DLCO increased to $39.63 \mathrm{~mL} / \mathrm{mmHg} / \mathrm{Mi}(130 \%)$ His serial spirometry with DLCO is given in Table 1 . He was managed with steroid and other supportive therapy and complete abstinence from plastic fumes exposure. In subsequent follow up after 3 years he showed improvement in symptoms and no further episode of hemoptysis. He was diagnosed to have diffuse alveolar hemorrhage due to trimellitic dust used in plastic industry.

\section{Discussion}

Trimellitic anhydride (TMA) dust/fumes results in clinical syndromes ranging from upper respiratory symptoms or asthma to

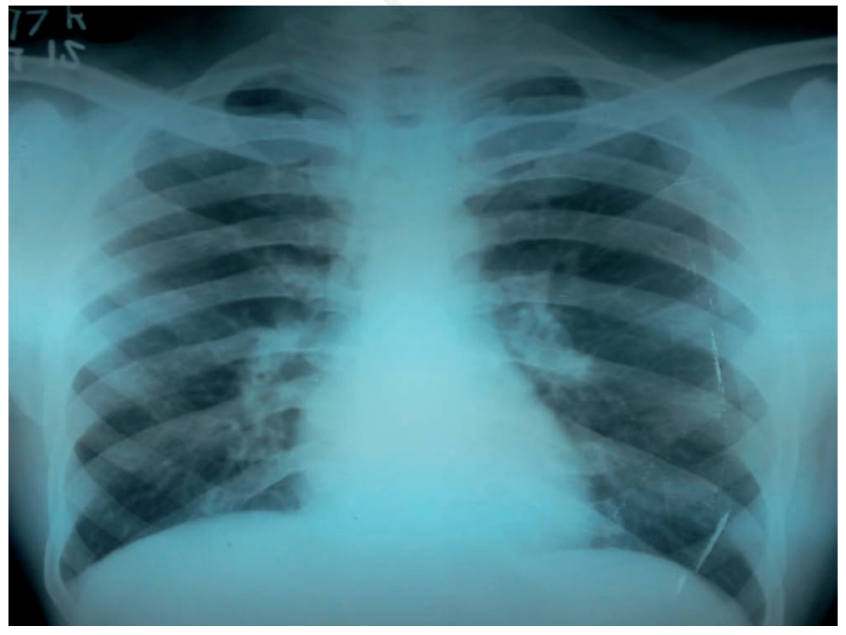

Figure 1. Chest radiograph (PA) view. wheezing and dyspnea due to immunological and irritant phenomenon [9]. After inhalation TMA acts as a hapten joining human albumin to become an antigen (Figure 4). The main etiopathogenesis in diffuse alveolar hemorrhage is the disruption of the alveolar
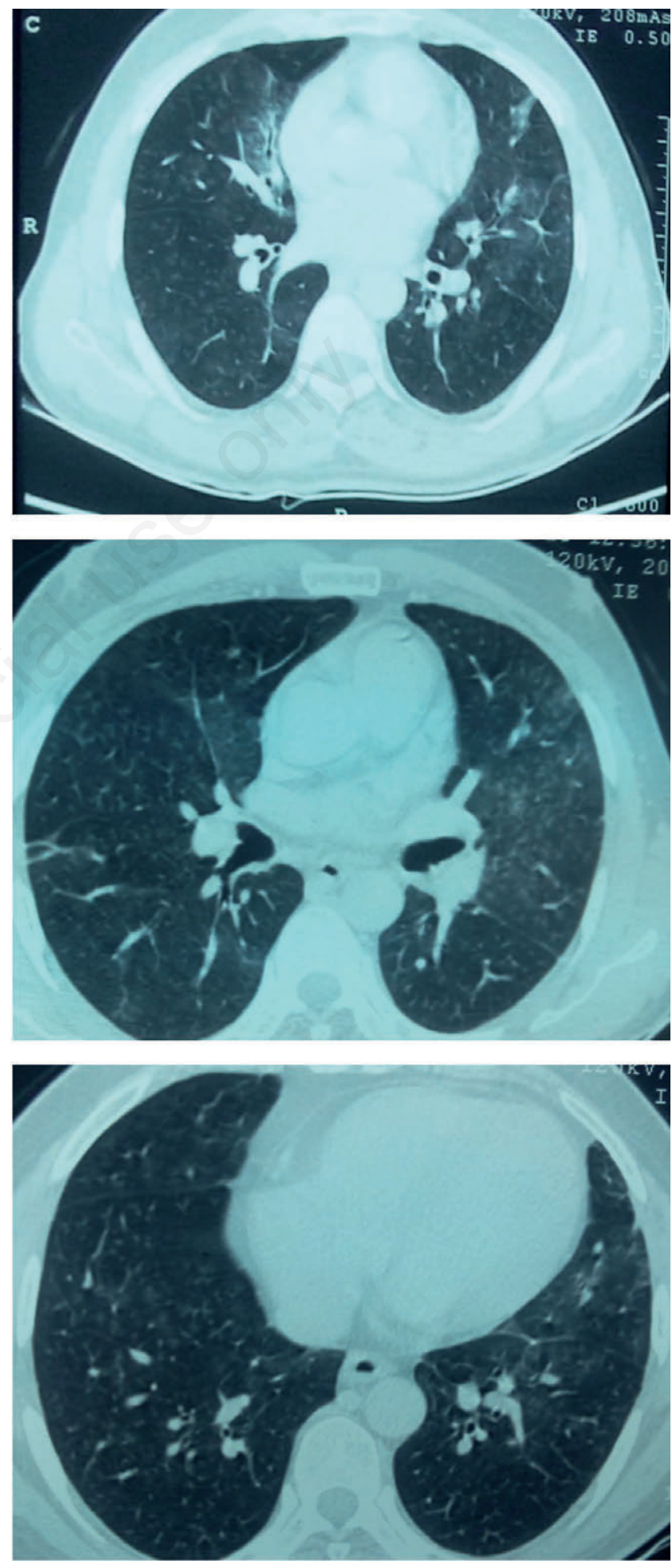

Figure 2. Computed tomography (CT) images showing bilateral ground glass attenuation with interlobular septal thickening. 
capillary membrane resulting in entry of erythrocytes in the functional respiratory unit [10]. Clinical manifestations are cough, hemoptysis, dyspnea and diffuse alveolar hemorrhage as seen in our case. In our case, upon re exposure to the culprit agent patient again started having same symptoms with increased DLCO on spirometry providing a contributory evidence to the role of trimellitic dust causing alveolar hemorrhage.

The subject was working in the same factory since last 12 years and was involved in the process of addition of plasticizers in PVC pipes. They are added to PVC to add flexibility. The complete process of manufacturing of PVC pipes includes melting of PVC granules into tubular pipe form after introducing to high temperature, by the process of extrusion follow by addition of plasticizers on heated pipes, cooling and then cutting them according to desired length. Our patient was involved in the process of spraying the plasticizers on PVC pipes since joining of this unit. The spraying modality consists of compounds, having TMA to be sprayed on PVC pipes when they are heated, resulting in inhalation of fumes. Our case presented after acute onset of haemoptysis, following exposure to the fumes after doing his routine duty. The TMA concentration at the work place however, was unknown .

DAH is caused primarily by vasculitis secondary to pulmonary capillaritis. Apart from vasculitis, cases pertaining to drugs, e.g. antiplatelets and low molecular weight heparin (LMWH) [11], amiodarone or narcotics abuse like marijuana or cocaine have been described in literature [12-14]. Infective etiology causing DAH includes viruses such as adenovirus, influenza virus, dengue virus, bacterial causes like leptospirosis, mycoplasma and staphylococcus and histoplasmosis [15-17]. In our case these causes were ruled out.

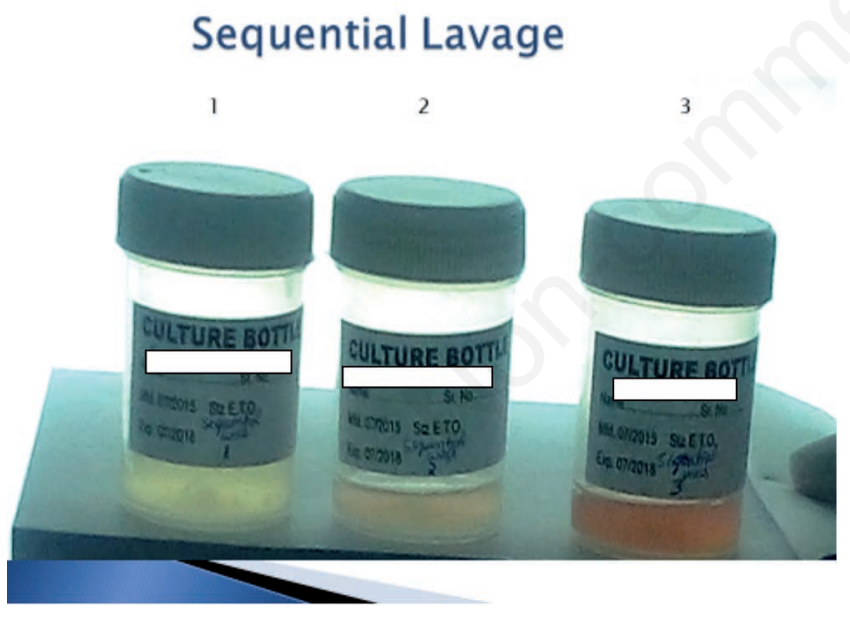

Figure 3. Progressive hemorrhagic nature of sequential lavage.
Alveolar hemorrhage secondary to plastic fumes is just tip of iceberg. Many studies have demonstrated its detrimental effect in human life. Other manifestations of plastic fumes include obliterative bronchiolitis, occupational asthma, hearing loss and end stage renal disease (ESRD) due to high exposure to solvents used in plastic industries [18-22]. Recent studies have demonstrated that phthalates which is used in PVC for softening has an impact on cardiovascular and autonomic function. Some reports have also suggested risk of diabetes, obesity, insulin resistance due to exposure to bisphenol-A, a type of plastic [23,24].

Engineering techniques to reduce exposure, at source of generation and use of personal protective equipment (PPE) can only help to diminish the risk of exposure to the occupationally exposed workers. In our case, the PPE were not used, only hand gloves

\section{Inhalation of trimellitic dust/fumes via inhalational route}

\begin{tabular}{|l|}
\hline $\begin{array}{l}\text { Systemic absorption of fumes and acting as } \\
\text { haptens }\end{array}$ \\
\hline $\begin{array}{l}\text { Hapten combine with human albumin to become } \\
\text { antigen hapten albumin complex (HAC) }\end{array}$ \\
\hline
\end{tabular}

\begin{tabular}{l} 
Activation of immunological cascade and \\
sensitization \\
\hline $\begin{array}{l}\text { Antigens causes capillaritis/alveolar } \\
\text { hemorrhage }\end{array}$ \\
\hline
\end{tabular}

Figure 4. Pathogenesis of Trimellitic dust/fumes in the disruption of alveolar capillary membrane.

Table 1. Sequential spirometry with diffusion capacity of carbon monoxide.

\begin{tabular}{lccc} 
Parameters & $\begin{array}{c}\text { On presentation } \\
\text { (post } 48 \mathrm{~h} \text { no hemoptysis period) }\end{array}$ & $\begin{array}{c}\text { After abstinence } \\
\text { from work for } 10 \text { days }\end{array}$ & $\begin{array}{l}48 \mathrm{~h} \text { of re-exposure } \\
\text { FEV1 }\end{array}$ \\
FVC & $3.00 \mathrm{~L}(83 \%)$ & $2.94 \mathrm{~L} \mathrm{(80 \% )}$ & $3.05 \mathrm{~L}(83 \%)$ \\
\hline FEV1/FVC & $4.67 \mathrm{~L}(109 \%)$ & $3.88 \mathrm{~L}(90 \%)$ & $3.99 \mathrm{~L} \mathrm{(92 \% )}$ \\
DLCO & $64.40(79 \%)$ & $75.87(93 \%)$ & $76.42(94 \%)$ \\
\hline
\end{tabular}

DLCO, diffusion capacity of carbon monoxide. 
were used and localized engineered control measures to curb the dust/fumes were not installed at the manufacturing unit, unrevealing the glaring reality in plastic industry.

To conclude, plastic exposure is an important cause of alveolar haemorrhage as it is preventable and requires complete abstinence to treat it.

\section{References}

1. Mapp CE. Agents, old and new, causing occupational asthma. Occup Environ Med 2001;58:354-60.

2. Broaddus VC, Mason R, Ernst JD, et al. Murray and Nadel's texbook of respiratory medicine, 6th ed. Philadelphia: Elsevier Saunders; 2016.

3. Grassin F, Andre M, Rallec B, et al. Alveolar hemorrhage fatal after "bang" of cannabis. Rev Mal Respir 2011;28:919-23.

4. Herbert FA, Orford R. Pulmonary hemorrhage and edema due to inhalation of resins containing tri-mellitic anhydride. Chest 1979;76:546-51.

5. Maltoni, C, Lefemine G. Carcinogenicity bioassays of vinyl chloride: I. Research plan and early results. Environ. Res. 1974;7:387-96.

6. Boxer B, Grammer LC, Harris K, et al. Six year clinical and immunologic follow up of workers exposed to trimellitic anhydride. J Allergy Clin Immunol 1987;80:147-52.

7. Saab H,Bajaj T, Bains K, Pacheco RG. Recurrent episodes of diffuse alveolar haemorrhage in systemic sclerosis 30 days apart. J Investig Med High Impact Case Rep 2019;7: 2324709619846594.

8. Zejnullahu K, Khatami S, Manesh RS. Diffuse alveolar haemorrhage: Blood, sweat and tears. J Gen Intern Med 2016;31:812-3.

9. Zeiss R, Patterson R, Pruzansky JJ, et al. Trimellitic anhydride-induced airway syndromes: clinical and immunological studies. J Allergy Clin Immunol 1977;60:96-103.

10. Dosi RA, Jain S, Jain A, et al. Diffuse alveolar hemorrhage: A very rare but catastrophic complication after percutaneous transluminal coronary angioplasty. J Assoc chest Physicians 2018;6:80-3.

11. Yildirim F, Kara I, Okuyan H, et al. Diffuse alveolar hemor- rhage associated with low molecular weight heparin and dual anti-platelet therapy after percutaneous coronary intervention. Clin Respir J 2017;11:1071-3.

12. Pendyal A. Diffuse alveolar hemorrhage secondary to amiodarone toxicity: a rare cause of cardiopulmonary decompensation in chronic systolic heart failure. J Am Coll Cardiol 2015;65:A622.

13. Shafi MI, Liaquat S, Auckley D. Up in smoke: An unusual case of diffuse alveolar hemorrhage from marijuana. Respir Med Case Rep 2018;25:22-4.

14. Dushay KM, Evans SK, Ghimire S, Liu J. Cocaine-induced diffuse alveolar hemorrhage: A case report and review of the literature. R I Med J 2016;99:34-6.

15. Von Ranke FM, Zanetti G, Hochhegger B, Marchiori E. Infectious diseases causing diffuse alveolar hemorrhage in immunocompetent patients: A state-of-the-art review. Lung 2013;191:9-18.

16. Ludwig B, Zotzmann V, Bode C, et al. Lethal pulmonary hemorrhage syndrome due to Leptospira infection transmitted by pet rat. ID cases 2017;8:84-6.

17. Grover K, Zainah H, Bhatnagar S, Stein T. A rare case of diffuse alveolar hemorrhage secondary to acute pulmonary histoplasmosis. Case Rep Infect Dis 2015;2015:821749.

18. Abdel-Rasoul GM, Abu-Salem ME, El Shazly HM, et al. Respiratory and auditory health disorders among workers in a plastic factory (industrial zone, Queisna City, Menoufia Governorate). Menoufia Med J 2016;29:757-61.

19. Helal SF, Elshafy WS. Health hazards among workers in plastic industry. Toxicol Ind Health 2013;29:81219.

20. Khaliq F, Singh P, Chandra P, et al. Pulmonary functions in plastic factory workers: a preliminary study. Indian J Physiol Pharmacol 2011; 55:60-6.

21. Cullinan P, McGavin C, Kreiss K, et al. Obliterative bronchiolitis in fiberglass workers: a new occupational disease? Occup Environ Med 2013;70:357-9.

22. Steenland NK, Thun MJ, Ferguson CW, Port FK. Occupational and other exposures associated with male end-stage renal disease: a case/control study. Am J Public Health 1990;80:153-7.

23. Provvisiero DP, Pivonello C, Muscogiuri G, et al. Influence of bisphenol A on type 2 diabetes mellitus. Int J Environ Res Public Health 2016;13:989.

24. Pjanic M. The role of polycarbonate monomer bisphenol-A in insulin resistance. Peer J 2017;5:e3809. 